Article

\title{
Comparisons of Chlorophyll Fluorescence and Physiological Characteristics of Wheat Seedlings Influenced by Iso-Osmotic Stresses from Polyethylene Glycol and Sodium Chloride
}

\author{
Chiu-Yueh Lan ${ }^{1}$, Kuan-Hung Lin ${ }^{2}{ }^{\oplus}$, Chun-Liang Chen ${ }^{1}$, Wen-Dar Huang ${ }^{1, *}$ and \\ Chang-Chang Chen ${ }^{3, *(1)}$ \\ 1 Department of Agronomy, National Taiwan University, Daan, Taipei 101, Taiwan; \\ donutstream@gmail.com (C.-Y.L.); tres635@ttes.gov.tw (C.-L.C.) \\ 2 Department of Horticulture and Biotechnology, Chinese Culture University, Shilin, Taipei 114, Taiwan; \\ rlin@faculty.pccu.edu.tw \\ 3 National Research Institute of Chinese Medicine, Ministry of Health and Welfare, Beitou, Taipei 112, Taiwan \\ * Correspondence: wendar@ntu.edu.tw (W.-D.H.); chencc@nricm.edu.tw (C.-C.C.); \\ Tel.: +886-2-3366-4762 (W.-D.H.); +886-2-2820-1999 (ext. 7071) (C.-C.C.); \\ Fax: $+886-2-2362-0879$ (W.-D.H.); +886-2-2826-4276 (C.-C.C.)
}

Received: 17 January 2020; Accepted: 26 February 2020; Published: 27 February 2020

check for updates

\begin{abstract}
Wheat (Triticum aestivum) cultivar Taichung SEL.2 (TCS2) is a salt-tolerance variety, but the mechanism involved remains unclear. This study aims to distinguish between the non-ionic osmotic and salt-mediated physiological effects on TCS2. Osmotic agents polyethylene glycol (PEG) and sodium chloride $(\mathrm{NaCl})$ were applied at three iso-osmotic levels, level 1 containing 24\% (w/v) PEG and $200 \mathrm{mM} \mathrm{NaCl}$, level 2 containing 26.5\% (w/v) PEG and $250 \mathrm{mM} \mathrm{NaCl}$ ), and level 3 containing $29 \%(w / v)$ PEG and $300 \mathrm{mM} \mathrm{NaCl}$, respectively. According to the investigation of chlorophyll fluorescence in the better $\mathrm{NaCl}$-treated seedlings, maximal quantum yield of photosystem II (PSII) $\left(\mathrm{F}_{\mathrm{v}} / \mathrm{F}_{\mathrm{m}}\right)$ and significant higher effective quantum yield of PSII ( $\left.\Phi_{\text {PSII }}\right)$ at level 3 were observed. Meanwhile, the non-photochemical quenching of PSII (NPQ) and the quantum yield of regulated energy dissipation of PSII [Y(NPQ)] were significantly higher in the NaCl-treated seedlings, and the quantum yield of non-regulated energy dissipation of PSII [Y(NO)] in the NaCl-treated seedlings was lower than the PEG-treated ones at level 2 and level 3. Furthermore, the less extensive degradation of photosynthetic pigments, the better ascorbate peroxidase (APX) activity and the less accumulation of malondialdehyde (MDA) were also observed in NaCl-treated seedlings. In the morphological traits, shoot elongation in $\mathrm{NaCl}$-treated seedlings was also preserved. These results suggest that TCS2 is more resistant to $\mathrm{NaCl}$-induced osmotic stress than to the PEG-induced stress. This study contributes to plant breeder interest in drought- and/or salt-tolerant wheat varieties.
\end{abstract}

Keywords: wheat; Triticum aestivum; salt stress; osmotic stress; APX activity

\section{Introduction}

Salinity in increasing frequency and intensity impacts wheat (Triticum aestivum) production around the world. It is estimated that more than $69 \%$ of wheat production is seriously influenced by high salinity [1]. Therefore, it is crucial to understand the mechanisms of salt stress tolerance in wheat and/or how to adapt to salt stress, and to discover how to prevent the impacts of salinity on wheat production. Salt stress would lead to osmotic and/or ionic stress over different time scales [2-4]. This osmotic and/or ionic stress would trigger signal sensing and induce overexpression of transcription factors to 
regulate downstream genes in plant sequentially. These regulated downstream genes would lead to the promotion of a biosynthetic pathway of osmolytes, such as proline, glycine betaine, trehalose, etc., the overexpression of transporter genes to stabilize both osmotic and ionic $\left(\mathrm{Na}^{+} / \mathrm{K}^{+}\right)$homeostasis, the increase of activities of antioxidative enzymes against stress-induced free radicals, and accumulation of polyamines [5]. A recent study also reported that aquaporins, which are a group of proteins regulating water transport, are also involved in the response to osmotic stress [6]. Furthermore, the moderate salt stress might induce salt adaptation in plant [7].

Salt stress might trigger a series of reactions that are similar to the physiological response to drought stress in a plant [8]. Almansouri et al. [9] reported that the iso-osmotic potential of $\mathrm{NaCl}$ has been imitated by polyethylene glycol (PEG), which is widely applied to stimulate osmotic stress. PEG is a non-ionic, neutral, and water-soluble polymer that does not penetrate roots [10]. The study of Marcińska et al. [11] reported that PEG-induced osmotic stress stimulated the higher accumulation of proline in drought-resistant wheat than in drought-sensitive one. Previous studies have found that PEG was more disadvantageous compared to $\mathrm{NaCl}$ treatments in the germination stage of durum wheat [9], and the seedling stage of wheat [3,10], Hordeum species [12], and Haloxylon aphyllum [13]. However, Muranaka et al. [14,15] found just the opposite in the seedling stage of wheat. Greenway and Munns [16] and Sharma et al. [17] evaluated salt-sensitive and -tolerant varieties and suggested that salt-tolerance varieties were more susceptible to PEG-induced water deficits compared to ionic stress, while there was an opposite response in sensitive types. Salinity resistance in plants also varies depending on the growth stage $[18,19]$. Sayar et al. [10] demonstrated that the seedling stage under iso-osmotic potential treatments was more susceptible to $\mathrm{NaCl}$ than the germination stage.

Each plant species/variety displays dynamic responses to salinity during different growth stages [18,19]. Plant species/varieties during specific growth stages lack a genetically related ability to reduce salt uptake $[20,21]$, compartmentalize salt in cell vacuoles, prevent salt from reaching toxic levels in leaves [4], and display more susceptibility to ion-induced stress. Furthermore, plant species/varieties during specific growth stages display a tolerance to ion-induced stress [22]. Both $\mathrm{Na}^{+}$and $\mathrm{Cl}^{-}$act as environmental signals that trigger rapid osmotic adjustment and stabilize shoot turgor $[23,24]$. NaCl-induced osmoregulation is much faster and less energy- and carbon-demanding than PEG-induced osmotic adjustment [25]. Recent research reported that wheat seedlings responded with different metabolic regulations to osmotic stress induced by $\mathrm{NaCl}$ and PEG [26].

To evaluate the relative influence of salt-induced osmotic and ionic stress, biochemical, physiological responses, and morphological traits can be investigated for the estimation of salt-tolerance mechanisms [27]. Under salt stresses, the enzymatic and non-enzymatic antioxidant systems, photosynthesis systems, and growth and development of a plant will be inhibited, but lipid peroxidation products will increase [28]. Recent research revealed that severe salt stress caused the accumulation of $\mathrm{H}_{2} \mathrm{O}_{2}$ and malondialdehyde (MDA), which is an indicator of lipid peroxidation products, and induced enzymatic antioxidant acitivities, while low salinity stimulated growth, photosynthesis, and promoted the activity of ascorbate peroxidase (APX) in plant [7].

Biochemical information responds to plant status under salt stress, but destructive biochemical assays will not allow real-time monitoring, whereas chlorophyll fluorescence (ChlF) analysis effectively estimates physiological changes and is a rapid and real-time screening system [29,30]. Recent studies reported that chlorophyll a fluorescence, also called prompt chlorophyll a fluorescence, and its parameters, which were calculated based on OJIP transient curves, effectively responded to shade [31], salt [32], light, heavy metal and other stress [33,34] in plant. Delayed chlorophyll a fluorescence, which is also reemitted from PSII antenna complex and displays multiple phase during emission time, was also recommended for monitoring of photosynthetic response under salt stresses [35]. Dabrowski et al. [36] revealed moderately integrating fluorescence parameters and gas exchange measurements would be applied for exploring the physiological response of plant to drought stress. However, Kalaji et al. [37] indicated that it was difficult to distinguish between the effects of drought and salinity by chlorophyll 
fluorescence parameters. Thus, the investigated ChlF parameters were integrated with growth analysis and biochemical assays for evaluating the effects of osmotic and ionic stress from salinity in this study.

Previously, we reported that wheat (Triticum aestivum) cultivar Taichung SEL. 2 (TCS2), one of the most widely cultivated cultivars in Taiwan, appears to be a salt-tolerant cultivar [38]. However, the salt-tolerant mechanisms of TCS2 are unclear. Therefore, the purpose of the present study is to evaluate the biochemical and physiological responses of TCS2 under iso-osmotic potentials induced by PEG and $\mathrm{NaCl}$ separately, followed by determining the salt-tolerance ability of TCS2 and its mechanisms. We hypothesized that TCS2 was more susceptible to the PEG-induced osmotic stress than the $\mathrm{NaCl}$-induced ionic toxic effect under different iso-osmotic levels stimulated with applied PEG and $\mathrm{NaCl}$, respectively.

\section{Materials and Methods}

\subsection{Plant and Growth Conditions}

Seeds of wheat (T. aestivum) cultivar TCS2 were collected from the Department of Agronomy, National Taiwan University, Taipei, Taiwan. Seeds were sterilized with $1 \%$ hydrogen peroxide for $5 \mathrm{~min}$, washed with distilled water, and then germinated in Petri dishes with wetted filter paper at $25^{\circ} \mathrm{C}$ in the dark. After $24 \mathrm{~h}$ dark incubation, uniformly germinated seeds were selected and cultivated in $150 \mathrm{~mL}$ beakers with complete Hoagland's nutrient solution (PhytoTech, Lenexa, KS, USA). Nutrient solutions were replaced every three days. Hydroponic wheat seedlings were raised in growth chambers under a 12/12 h day/night photoperiod at $300 \mu \mathrm{mol} \mathrm{m}^{-2} \mathrm{~s}^{-1}$ photosynthetic photon flux density (PPFD) with $25 / 20^{\circ} \mathrm{C}$ day/night temperature.

\subsection{Experimental Treatments}

Hydroponic seedlings that reached stage Z1.0 [39] on day 6 were treated with the osmotic agents polyethylene glycol (PEG-6000, Sigma-Aldrich) and $\mathrm{NaCl}$ separately according to the treatment design for seven days. According to the treatments from Almansouri et al. [9], these osmotic agents were used to prepare three iso-osmotic levels respectively, level 1 containing $24 \%(w / v)$ PEG or $200 \mathrm{mM} \mathrm{NaCl}$, level 2 containing 26.5\% (w/v) PEG or $250 \mathrm{mM} \mathrm{NaCl}$, and level 3 containing 29\% (w/v) PEG or $300 \mathrm{mM}$ $\mathrm{NaCl}$. Treatment without PEG and $\mathrm{NaCl}$ application was considered as control (CT). The experiment was independently performed three times for a randomized design of growth conditions.

\subsection{Growth Analysis}

Shoot height and root length of hydroponic seedlings were determined with a ruler manually before measuring chlorophyll fluorescence (ChlF) and sample collection.

\subsection{Measurements of ChlF}

The parameters of ChlF in seedling leaves were determined after PEG and salt treatments. ChlF was measured in the middle portion of the first leaf of each seedling taken at ambient temperature with Chl fluorometer imaging-PAM (Walz, Effeltrich, Germany). Plant materials were dark adapted for $20 \mathrm{~min}$ before ChlF measurements. Actinic light and saturating light intensities were set to 185 and $7200 \mu \mathrm{mol} \mathrm{m} \mathrm{m}^{-2} \mathrm{~s}^{-1}$ of photosynthetically active radiation (PAR), respectively. According to previously described methods $[31,40,41]$ the maximum quantum yield of PSII $\left(\mathrm{F}_{\mathrm{v}} / \mathrm{F}_{\mathrm{m}}\right)$, effective quantum yield of PSII ( $\left.\Phi_{\mathrm{PSII}}\right)$, non-photochemical quenching of PSII (NPQ), quantum yield of regulated energy dissipation of PSII [Y(NPQ)], and quantum yield of non-regulated energy dissipation of PSII [Y(NO)] were determined.

\subsection{Measurement of APX Activity}

APX activity was measured based on the method of Nakano and Asada [42]. Briefly, $0.1 \mathrm{~g}$ of the last newly expanded leaf was ground and extracted with $2 \mathrm{~mL}$ of sodium phosphate buffer $(50 \mathrm{mM}$, 
$\mathrm{pH}$ 6.8) in an ice bath, and then centrifuged at $4{ }^{\circ} \mathrm{C}$ and $12,000 \mathrm{rpm}$ for $20 \mathrm{~min}$. The supernatant $(0.1 \mathrm{~mL})$ was collected, and mixed with $2.7 \mathrm{~mL}$ of potassium phosphate buffer $(150 \mathrm{mM}, \mathrm{pH} 7.0), 0.4 \mathrm{~mL}$ of ethylenediaminetetraacetic acid (EDTA, $0.75 \mathrm{mM}), 0.5 \mathrm{~mL}$ of $\mathrm{H}_{2} \mathrm{O}_{2}(6 \mathrm{mM}), 0.5 \mathrm{~mL}$ of $\mathrm{H}_{2} \mathrm{O}$, and $0.5 \mathrm{~mL}$ of ascorbate $(1.5 \mathrm{mM})$ sequentially. The APX activity of sample solution was determined by a spectrophotometer (Hitachi U3010, Tokyo, Japan) at $290 \mathrm{~nm}$. A blank containing the same mixture without sample extract was also determined.

\subsection{Determination of Photosynthetic Pigment Concentration}

The concentrations of photosynthetic pigments were determined according to the method of Yang et al. [43]. Briefly, $0.01 \mathrm{~g}$ of lyophilized sample powder was extracted with $12 \mathrm{~mL} 80 \%$ acetone solution, and then centrifuged at $4500 \mathrm{rpm}$ for $5 \mathrm{~min}$. The supernatant of the sample extract was collected. The concentrations of $\mathrm{Chl} a, \mathrm{Chl} b$, and carotenoids (Car) in sample solution was determined by a spectrophotometer (Hitachi U3010, Tokyo, Japan) at 663.6, 646.6, and $440.5 \mathrm{~nm}$, respectively. A blank containing the same solvent without sample extract was also determined.

\subsection{Determination of MDA Concentration}

MDA was determined according to the method of Heath and Packer [44]. Briefly, $0.03 \mathrm{~g}$ of lyophilized sample powder was ground and extracted with $1 \mathrm{~mL}$ of $5 \% \mathrm{TCA}$, and then centrifuged at $10,000 \mathrm{rpm}$ and $20^{\circ} \mathrm{C}$ for $5 \mathrm{~min}$. The supernatant $(250 \mu \mathrm{L})$ was collected and mixed with $1 \mathrm{~mL}$ of $0.5 \%$ thiobarbituric acid (TBA), which was made up with $20 \%$ TCA. The mixture was incubated at $95^{\circ} \mathrm{C}$ for 30 min with a water bath, and then immediately cooled in an ice bath. The reaction mixture was centrifuged at $3000 \mathrm{rpm}$ and $20^{\circ} \mathrm{C}$ for $10 \mathrm{~min}$. The MDA concentration of sample mixtures was determined by a spectrophotometer (Hitachi U3010, Tokyo, Japan) at 532 and $600 \mathrm{~nm}$. A blank containing the same reaction mixture without sample extract was also determined.

\subsection{Statistical Analyses}

All determined data were subjected to statistical analysis by using analysis of variance (ANOVA) followed by a least significant difference (LSD) test and $t$-test at $p<0.05$. All statistical analyses were conducted using R i386 3.5.1 software (https://cran.r-project.org/bin/windows).

\section{Results}

\subsection{Growth Analysis}

The shoot heights and root lengths of NaCl- and PEG-treated seedlings are presented in Figure 1. The average shoot height of non-treated (CT) seedlings was $24.3 \mathrm{~cm}$. Shoot heights of the PEG-treated seedlings declined dramatically to $12.6 \mathrm{~cm}$ at osmotic level 1 [24\% $(w / v)$ PEG] and then decreased gradually to $11.6 \mathrm{~cm}$ at osmotic level 3 [29\% (w/v) PEG]. A similar declining trend was observed in the NaCl-treated seedlings. However, the shoot heights of NaCl-treated seedlings were significantly higher than in PEG-treated seedlings under the iso-osmotic potential treatments. The trend in root length under PEG and $\mathrm{NaCl}$ treatment was similar to the trend in shoot height. 


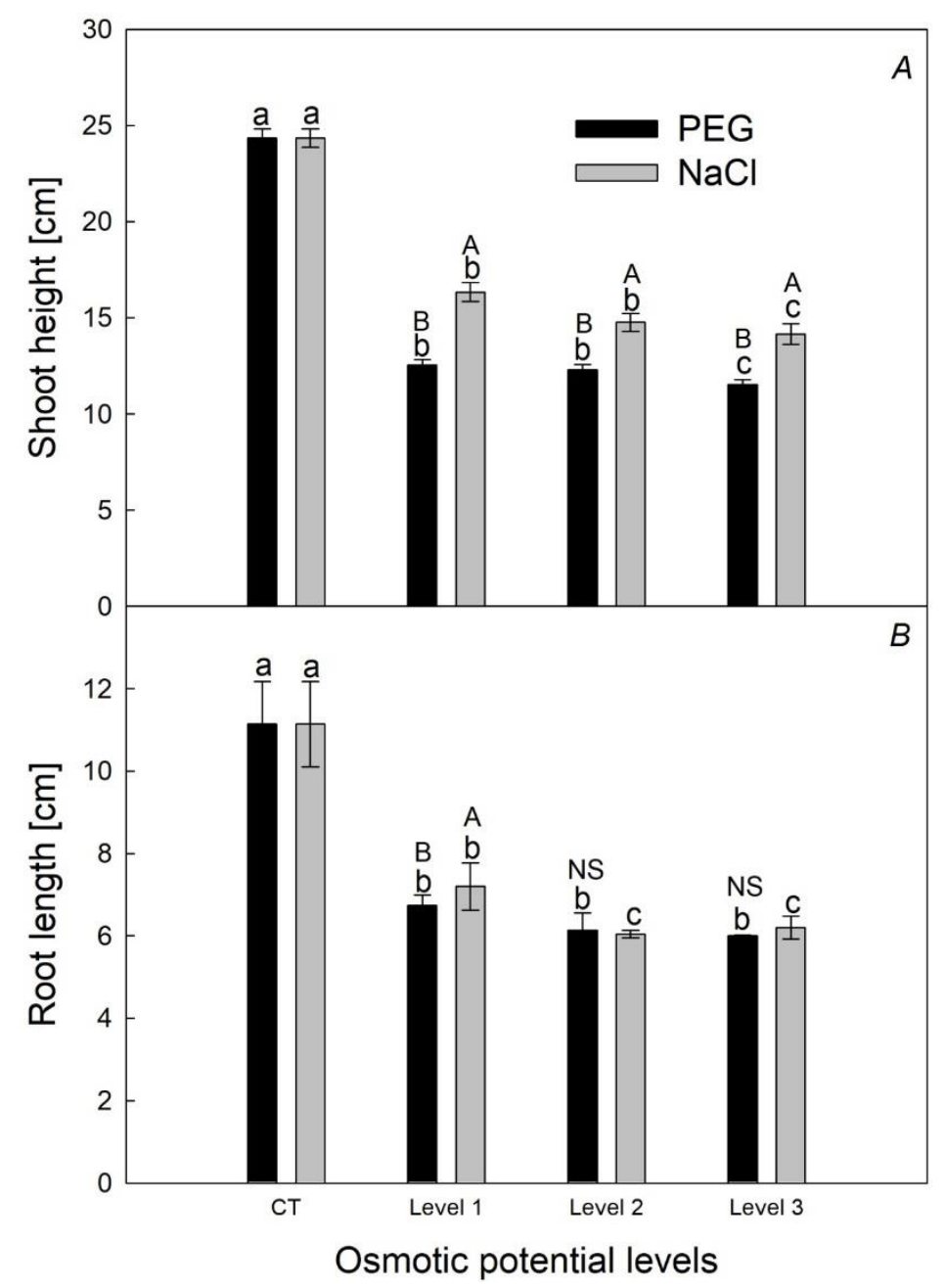

Figure 1. Means $\pm S D(n=5)$ of shoot height $(A)$ and root length $(\mathrm{cm})(\mathbf{B})$ from seedlings grown under three iso-osmotic potential levels under separate polyethylene glycol (PEG) and sodium chloride $(\mathrm{NaCl})$ treatments. Level 1: 24\% (w/v) PEG and $200 \mathrm{mM} \mathrm{NaCl}$; Level 2: 26.5\% (w/v) PEG and $250 \mathrm{mM} \mathrm{NaCl}$; Level 3: 29\% (w/v) PEG and $300 \mathrm{mM} \mathrm{NaCl}$. Non-treated control (CT) shown twice was easy for the identification of $\mathrm{NaCl}$ and PEG treatment. Means with different lowercase letters significantly differ in a least significant difference (LSD) test under different PEG or $\mathrm{NaCl}$ concentrations, respectively $(p<0.05)$. Means with different capital letters significantly differ in a $t$-test between PEG and $\mathrm{NaCl}$ concentration at the same osmotic potential.

\subsection{ChlF}

$\mathrm{F}_{\mathrm{V}} / \mathrm{F}_{\mathrm{m}}$ and $\Phi_{\mathrm{PSII}}$ in leaves are the indexes of the maximum and effective quantum yield of PSII, respectively. These two indexes have to be determined after dark adaption and under illumination, and are widely used to estimate the status of plants under stress [45]. Figure 2 shows that the value of $\mathrm{F}_{\mathrm{v}} / \mathrm{F}_{\mathrm{m}}$ in the leaves of non-treated (CT) seedlings was 0.781 , and the $\mathrm{F}_{\mathrm{v}} / \mathrm{F}_{\mathrm{m}}$ of the seedlings under PEG treatment declined dramatically to 0.019 . However, the $\mathrm{F}_{\mathrm{v}} / \mathrm{F}_{\mathrm{m}}$ of seedlings under $\mathrm{NaCl}$ treatment was stable until osmotic level $3(300 \mathrm{mM} \mathrm{NaCl})$. Furthermore, the $\mathrm{F}_{\mathrm{v}} / \mathrm{F}_{\mathrm{m}}$ values of $\mathrm{NaCl}$-treated seedlings were significantly higher than for PEG-treated seedlings under iso-osmotic potential treatments. $\Phi_{\text {PSII }}$ in the leaves of seedlings with PEG treatment declined from 0.526 to 0.013 with increasing PEG concentrations. The $\Phi_{\text {PSII }}$ in the leaves of seedlings with $\mathrm{NaCl}$ treatment showed a similar trend to the

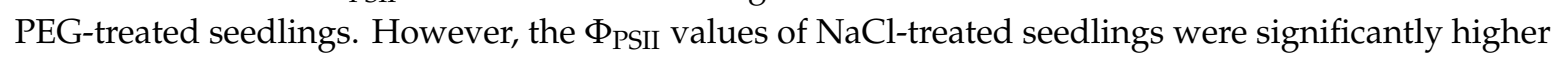
than for PEG-treated seedlings at osmotic level 3 (Figure 3A).

NPQ represents the non-photochemical quenching of PSII, while $Y(N P Q)$ and $Y(N O)$ are important fluorescence parameters of photo-protection and photo-damage, respectively [41]. NPQ in the leaves of 
the PEG-treated seedlings declined dramatically from 0.22 to 0.00 with increasing PEG concentrations. On the other hand, the NPQ of NaCl-treated seedlings increased suddenly at osmotic level 2, and then gradually decreased to the level of the CT seedlings. The NPQ values in the leaves of NaCl-treated seedlings were always significantly higher than in PEG-treated seedlings under the same osmotic potential treatments (Figure 3B). A similar dynamic was observed in Y(NPQ) in the leaves of PEG and $\mathrm{NaCl}$-treated seedlings (Figure $3 \mathrm{C}$ ). Both PEG and $\mathrm{NaCl}$ applications increased $\mathrm{Y}(\mathrm{NO})$ values, while the PEG-treated seedlings exhibited significantly higher $\mathrm{Y}(\mathrm{NO})$ values than the $\mathrm{NaCl}$-treated seedlings (Figure 3D).
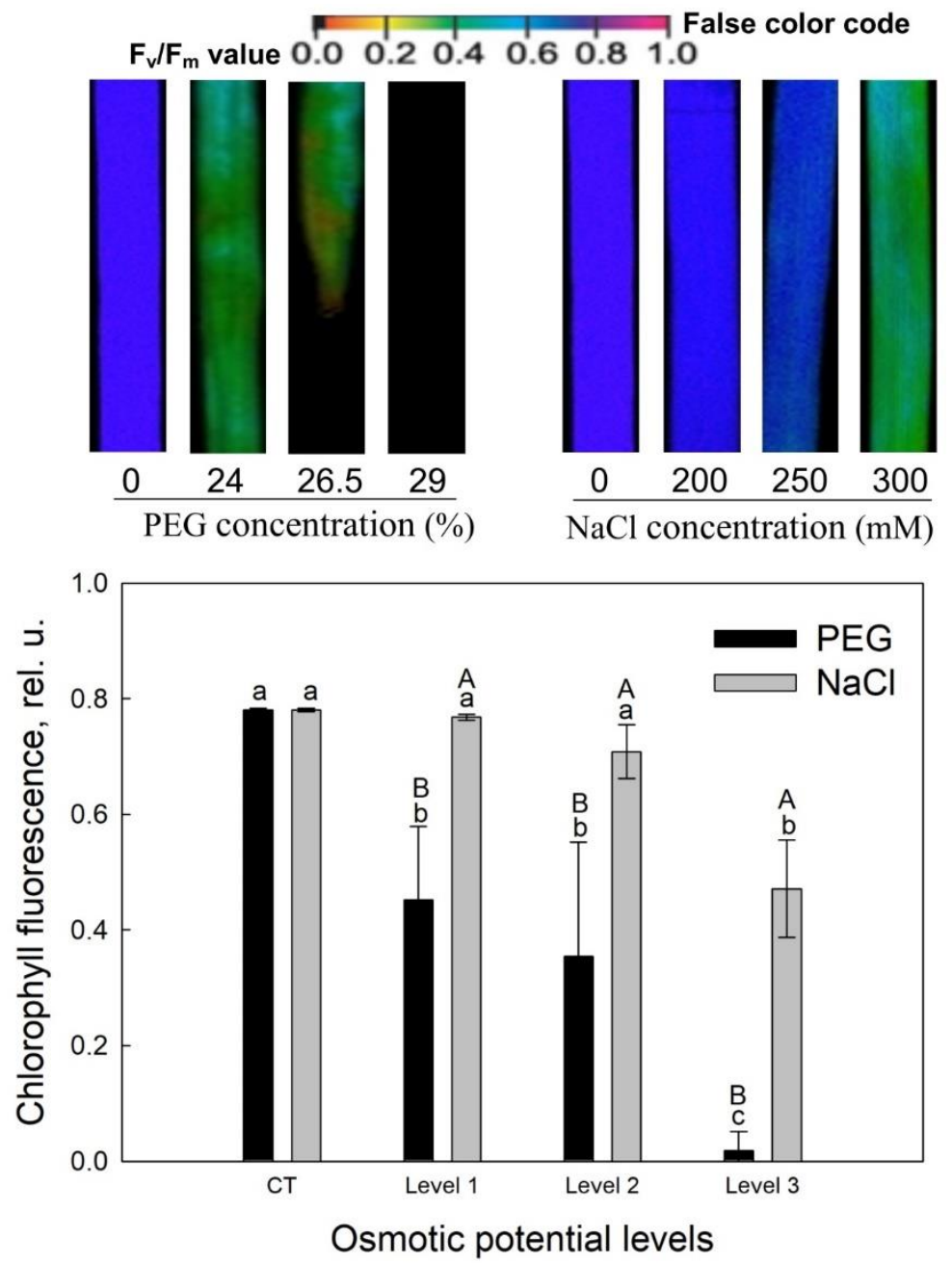

Figure 2. Images and the mean $\pm \mathrm{SD}(\mathrm{n}=3)$ of the maximum quantum yield of photosynthetic system II $\left(\mathrm{F}_{\mathrm{v}} / \mathrm{F}_{\mathrm{m}}\right)$ of leaves collected from seedlings grown under three iso-osmotic potential levels under separate PEG and NaCl treatments. Level 1: 24\% (w/v) PEG and $200 \mathrm{mM} \mathrm{NaCl}$; Level 2: 26.5\% (w/v) PEG and $250 \mathrm{mM} \mathrm{NaCl}$; Level 3: 29\% (w/v) PEG and $300 \mathrm{mM} \mathrm{NaCl}$. Means with different lowercase letters significantly differ in an LSD test under different PEG or $\mathrm{NaCl}$ concentrations, respectively $(p<0.05)$. Means with different capital letters significantly differ in a $t$-test between PEG and $\mathrm{NaCl}$ concentration at the same osmotic potential level. The false color code depicted on the top of the images ranges from 0.0 (black) to 1.0 (purple). 


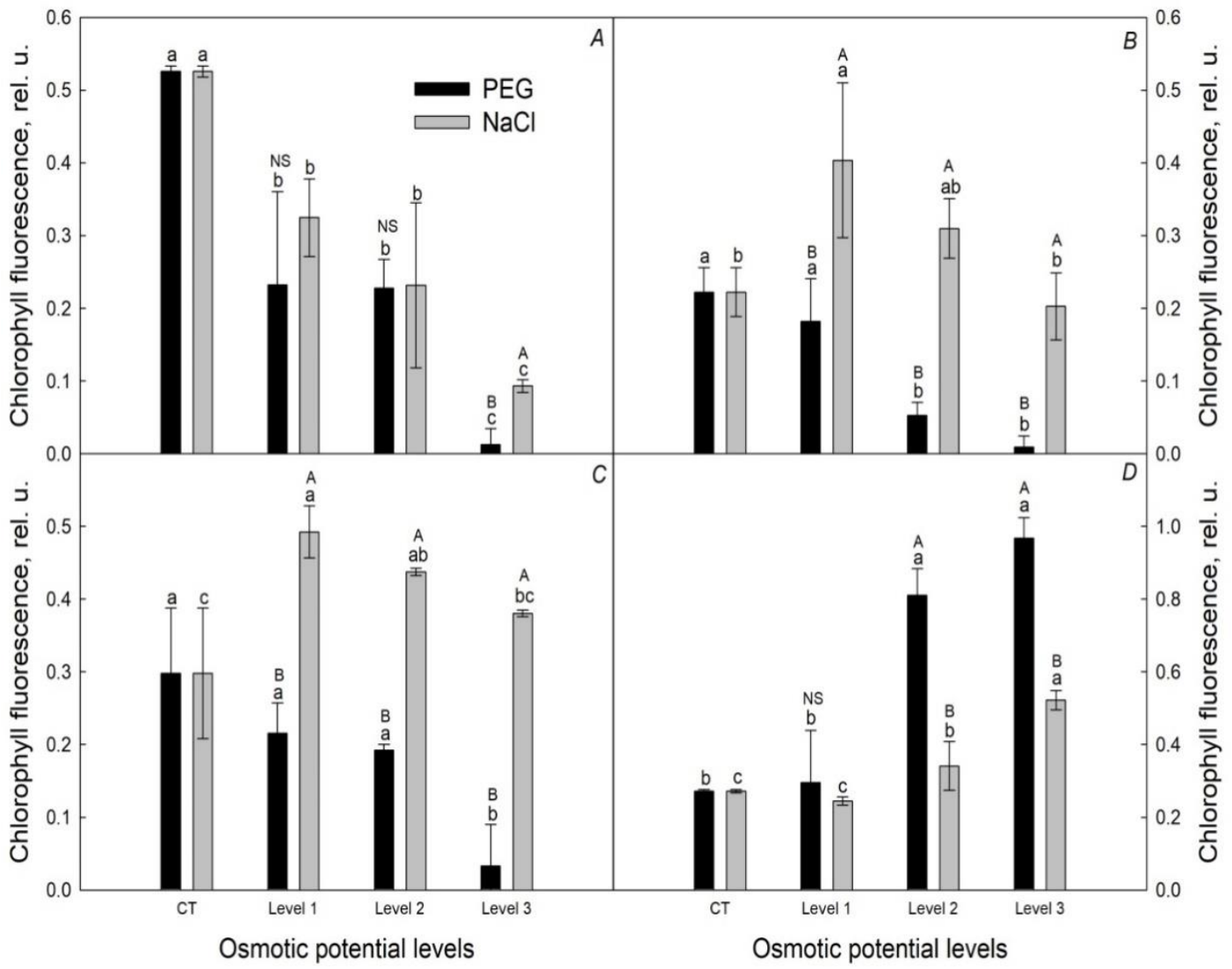

Figure 3. Means $\pm \mathrm{SD}(\mathrm{n}=3)$ of the effective quantum yield of photosystem II under illumination $\left(\Phi_{\mathrm{PSII}}\right)(\mathrm{A})$ non-photochemical quenching (NPQ); (B) quantum yield of regulated energy dissipation of photosystem II [Y(NPQ)]; (C) quantum yield of non-regulated energy dissipation of photosystem II [Y(NO)]; (D) of leaves collected from seedlings grown under three iso-osmotic potential levels with separate PEG and NaCl treatments. Level 1: 24\% (w/v) PEG and $200 \mathrm{mM} \mathrm{NaCl}$; Level 2: 26.5\% (w/v) PEG and $250 \mathrm{mM} \mathrm{NaCl}$; Level 3: 29\% (w/v) PEG and $300 \mathrm{mM} \mathrm{NaCl}$. Means with different lowercase letters significantly differ in an LSD test under different PEG or $\mathrm{NaCl}$ concentrations, respectively $(p<0.05)$. Means with different capital letters significantly differ in a $t$-test between PEG and $\mathrm{NaCl}$ concentration at the same osmotic potential level.

\subsection{APX Activity}

The results of the APX activity measured in the wheat seedlings in this study are presented in Figure 4. The APX activity of PEG- and NaCl-treated seedlings both showed descending trends. Furthermore, APX activity in NaCl-treated seedlings was significantly higher than in PEG-treated seedlings under the same iso-osmotic potential. 


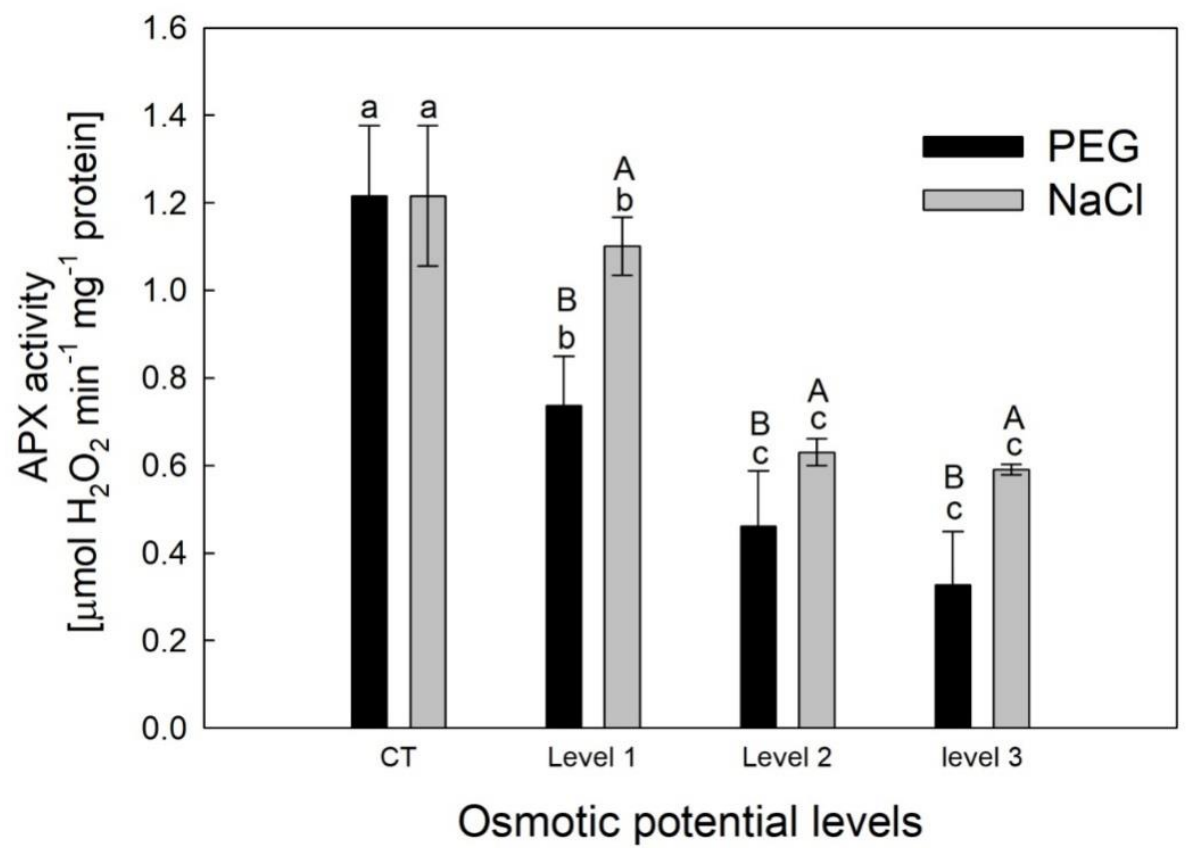

Figure 4. Means $\pm S D(n=3)$ of ascorbate peroxidase (APX) activity of leaves collected from seedlings grown under three iso-osmotic potential levels under separate PEG and $\mathrm{NaCl}$ treatments. Level 1: 24\% $(w / v)$ PEG and $200 \mathrm{mM} \mathrm{NaCl}$; Level 2: 26.5\% (w/v) PEG and $250 \mathrm{mM} \mathrm{NaCl}$; Level 3: 29\% (w/v) PEG and $300 \mathrm{mM} \mathrm{NaCl}$. Means with different lowercase letters significantly differ in an LSD test under different $\mathrm{PEG}$ or $\mathrm{NaCl}$ concentrations, respectively $(p<0.05)$. Means with different capital letters significantly differ in a $t$-test between PEG and $\mathrm{NaCl}$ concentration at the same osmotic potential level.

\subsection{Photosynthetic Pigments}

The Chl $a, b$, and total Chl concentrations of PEG and NaCl-treated seedlings all showed descending trends, and the concentrations of these pigments in $\mathrm{NaCl}$-treated seedlings were significantly higher than in PEG-treated seedlings under the same iso-osmotic potential (Table 1). The Car concentration in the non-treated seedlings was $1.40 \mathrm{mg} \mathrm{g}^{-1} \mathrm{DW}$. In the PEG-treated seedlings, Car concentrations decreased significantly but stayed at a stable level $\left(0.81-0.84 \mathrm{mg} \mathrm{g}^{-1} \mathrm{DW}\right)$. A similar trend was also observed in the Car concentrations of the $\mathrm{NaCl}$-treated seedlings, and Car concentrations in $\mathrm{NaCl}$-treated seedlings were always significantly higher $\left(0.87-0.92 \mathrm{mg} \mathrm{g}^{-1} \mathrm{DW}\right)(p<0.05)$ than in PEG-treated seedlings under iso-osmotic potential treatment.

Table 1. Means \pm SD of chlorophyll (Chl $a, \mathrm{Chl} b$, total Chl) and carotenoids (Car) in leaves collected from seedlings growing under three iso-osmotic potential levels under separate PEG and $\mathrm{NaCl}$ treatments.

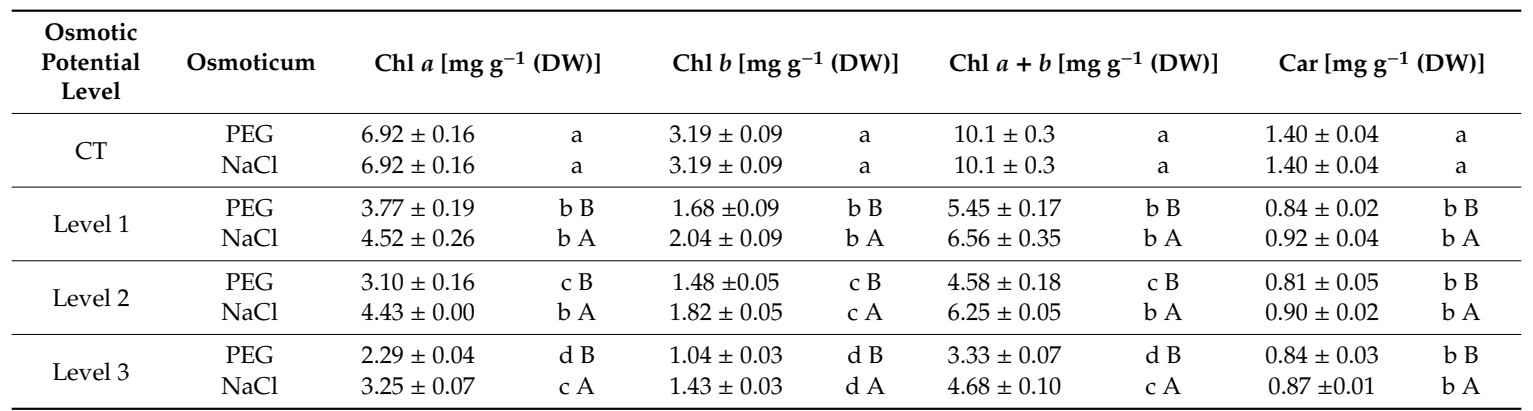

Values are the mean $\pm \mathrm{SD}(\mathrm{n}=3)$. Level 1: $24 \%(w / v)$ PEG and $200 \mathrm{mM} \mathrm{NaCl}$; Level 2: $26.5 \%(w / v)$ PEG and $250 \mathrm{mM}$ $\mathrm{NaCl}$; Level 3: 29\% (w/v) PEG and $300 \mathrm{mM} \mathrm{NaCl}$. Means with different lowercase letters significantly differ in an LSD test under different PEG or $\mathrm{NaCl}$ concentrations, respectively $(p<0.05)$. Means with different capital letters significantly differ in a $t$-test between PEG and $\mathrm{NaCl}$ concentration at the same osmotic potential level. CT, Control. Chl, chlorophyll. Car, carotenoids. 


\subsection{MDA Concentration}

Figure 5 reveals that the MDA concentration of non-treated seedlings was $13.5 \mathrm{nmol} \mathrm{g}{ }^{-1} \mathrm{DW}$. The MDA concentrations of seedlings with PEG treatments increased dramatically to $116.7 \mathrm{nmol}$ $\mathrm{g}^{-1}$ DW at osmotic level $3(29 \%(w / v)$ PEG), while the MDA concentration in NaCl-treated seedlings increased slightly to $33.2 \mathrm{nmol} \mathrm{g}^{-1} \mathrm{DW}$ at the same osmotic potential $(300 \mathrm{mM} \mathrm{NaCl})$. Furthermore, the differences in MDA concentrations of $\mathrm{NaCl}$-treated seedlings were insignificant among all $\mathrm{NaCl}$ treatments. The MDA concentrations of PEG-treated seedlings were significantly higher than in $\mathrm{NaCl}$-treated seedlings under iso-osmotic potential treatment.

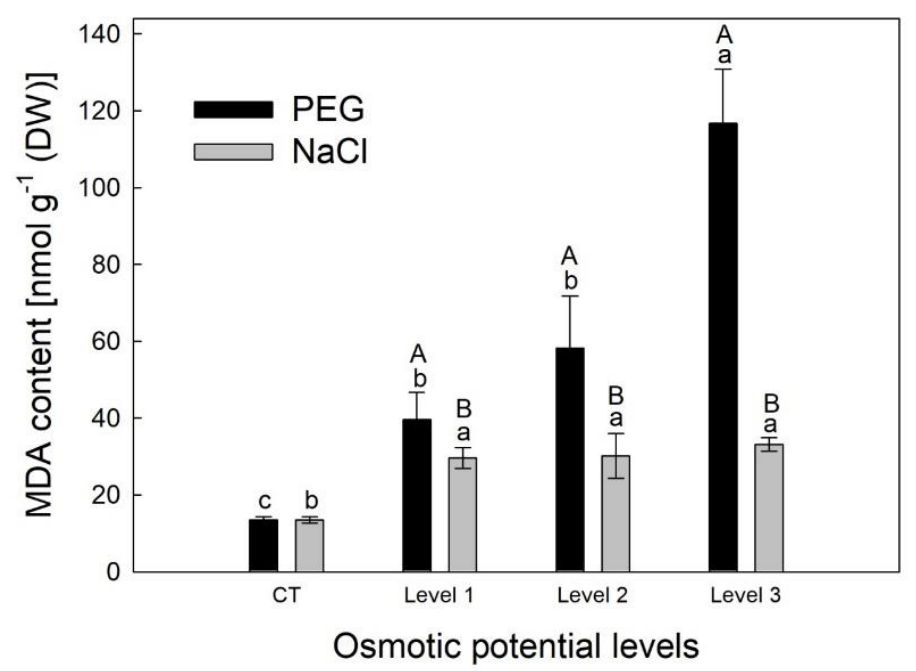

Figure 5. Means $\pm \mathrm{SD}(\mathrm{n}=3)$ of the malondialdehyde (MDA) content of leaves collected from seedlings grown under three iso-osmotic potential levels under separate PEG and NaCl treatments. Level 1: 24\% $(w / v)$ PEG and $200 \mathrm{mM} \mathrm{NaCl}$; Level 2: 26.5\% (w/v) PEG and $250 \mathrm{mM} \mathrm{NaCl}$; Level 3: 29\% (w/v) PEG and $300 \mathrm{mM} \mathrm{NaCl}$. Means with different lowercase letters significantly differ in an LSD test under different $\mathrm{PEG}$ or $\mathrm{NaCl}$ concentrations, respectively $(p<0.05)$. Means with different capital letters significantly differ in a $t$-test between PEG and $\mathrm{NaCl}$ concentration at the same osmotic potential.

\section{Discussion}

In order to investigate the osmotic and ionic effects from salt stress, the growth and physiological status of PEG- and/or NaCl-treated seedlings grown under three iso-osmotic levels were evaluated in this study. The treatment concentrations of PEG and $\mathrm{NaCl}$ are based on the morphological symptoms of osmotic and ion-toxic effects on wheat leaves. The obvious symptoms of water deficits are leaf wilting and rolling because of stomatal closure in PEG-induced osmotic stress [3], while ion-excess symptoms in NaCl-induced stress are chlorotic or senescent leaves [4]. The durations of osmotic treatments based on PEG- and/or- NaCl-induced symptoms are observable and obvious, and lead to irreversible damage to wheat [3]. The ChIF of PSII can then be determined for early monitoring.

The $\mathrm{F}_{\mathrm{v}} / \mathrm{F}_{\mathrm{m}}$, which is one of the parameters of prompt chlorophyll fluorescence, was determined after dark adapt for $20 \mathrm{~min}$. Previous study revealed that $\mathrm{F}_{\mathrm{v}} / \mathrm{F}_{\mathrm{v}}$ in plant effectively responded to $\mathrm{NaCl}$, PEG, light, and heavy metal stress [34]. In this study, Fv/Fm values in the PEG-treated seedlings declined significantly with raising osmotic level, while the decrease of $\mathrm{Fv} / \mathrm{Fm}$ in the $\mathrm{NaCl}$-treated group was only observed at level $3(300 \mathrm{mM} \mathrm{NaCl})$ (Figure 2). The investigation of $\mathrm{F}_{\mathrm{v}} / \mathrm{F}_{\mathrm{m}}$ in the study [37] also revealed that the changes of $\mathrm{F}_{\mathrm{v}} / \mathrm{F}_{\mathrm{m}}$ in Tilia cordata under salinity and drought stress showed different dynamics. In addition, the dynamic of $\mathrm{F}_{\mathrm{v}} / \mathrm{F}_{\mathrm{m}}$ was correlated to photosynthetic rate in sugarcane under osmotic stress [46]. However, Dabrowski et al. [31] indicated that only $F_{v} / F_{m}$ did not reliably reflect photosynthetic rate in shade-treated Lolium perenne. Recent studies surveyed multiple parameters of prompt and delayed ChlF and observed several parameters highly correlated to photosynthetic rate in Lolium perenne $[35,36]$. 
Recent studies integrated multiple ChlF parameters for evaluating the PSII function under salt [32,35] and drought stress [36]. Other ChlF parameters such as $\Phi_{\mathrm{PSII}}, \mathrm{NPQ}, \mathrm{Y}(\mathrm{NPQ})$, and $\mathrm{Y}(\mathrm{NO})$ were calculated from ChlF signals that were determined with continuous actin light [41]. The photons absorbed by PSII would be divided into three complementary quantum yields, $\Phi_{\mathrm{PSII}}$ (also known as $\mathrm{Y}(\mathrm{II})), \mathrm{Y}(\mathrm{NPQ})$, and $\mathrm{Y}(\mathrm{NO})$. In this study, all $\Phi_{\mathrm{PSII}}$ in osmotic treatments were significant decreased (Figure $3 \mathrm{~A}$ ), and this result suggested that the osmotic treatment groups performed lower degree photons, absorbed by PSII used in photochemistry, than control group. Furthermore, the $\Phi_{\mathrm{PSII}}$ difference between PEG- and NaCl-treated seedlings was insignificant except at osmotic level 3 (Figure 3A), indicating that the PSII capability in the photochemical reaction was damaged by both PEG and $\mathrm{NaCl}$. Muranaka et al. [14] and Flagella et al. [47] also report that $\Phi_{\mathrm{PSII}}$ was influenced under extreme water deficit. The study of Suriyan and Chalermpol [46] also supported osmotic stress reduced $\Phi_{\mathrm{PSII}}$ in plant.

The values of NPQ and $\mathrm{Y}(\mathrm{NPQ})$ in the NaCl-treated seedlings were significant higher but slightly declined with raising $\mathrm{NaCl}$ concentration, whereas the values of $\mathrm{Y}(\mathrm{NO})$ in the PEG-treated seedlings were significant higher at osmotic level 2 and 3 (Figure 3B,D). These results suggested that the capacity of PSII for processing photochemistry in seedlings might be inhibited under $\mathrm{NaCl}$ stress, while the excessive energy would be dissipated through regulated NPQ pathway, such as xanthophyll cycle [41]. One the other hand, PEG-induced stress also inhibited PSII capacity for processing photochemistry, but this osmotic stress did not induce the NPQ-mechanism. The dynamics of these parameters reflected the various effects of osmotic and ionic stress on ChlF in wheat TCS2 seedling (Figure 3). Suriyan and Chalermpol [46] revealed NPQ and proline in leaves of plant responded to the iso-osmotic levels, and different dynamics of ChlF were also observed. ChlF parameters were well applied to monitoring plant response to various abiotic stresses [33,34], but it was still difficult to distinguish between drought and salinity stress by ChlF [37].

Photosynthetic pigments, including $\mathrm{Chl} a, \mathrm{Chl} b$, and Car, provide the light-harvesting function that is essential for photosynthesis [29]. In addition, Car also absorbs excessive light to protect chlorophyll from excessive light-loading and further damage. Car-provided protection is known as photoprotection [48]. In this study, the accumulation of Chl sharply dropped in all of the treated seedlings with increasing treatment concentration (Table 1). However, the concentration of Chl $a$, Chla $b$, and their sum were influenced more by PEG-induced osmotic stress than $\mathrm{NaCl}$ treatment at all levels of iso-osmotic potential. These results suggest that the osmotic stress-induced damage was more severe in PEG-treated seedlings. In this study, PEG and $\mathrm{NaCl}$ treatments also strongly inhibited Car accumulation, and PEG treatments reduced Car concentrations in wheat seedlings more significantly than $\mathrm{NaCl}$ treatments. Car accumulation results indicate that Car provided photoprotection in $\mathrm{NaCl}$-treated seedlings better than in PEG-treated seedlings (Table 1). These results indicate that the mechanisms involved are highly species dependent. Nxele et al. [8] published that both drought and salinity inhibited the accumulation of Chl in sorghum, but a more severe decrease in Chl was observed under salinity. The study on sugarcane also revealed $\mathrm{NaCl}$-induced stress leaded to more degradation of $\mathrm{Chl}$ and Car in plant, and the $\mathrm{Chl}$ content was highly correlated to photosynthetic rate [46]. The recent study on sugar beet indicated that photosynthesis capability and the accumulation of $\mathrm{Chl}$ were induced at moderate salinity $(75-100 \mathrm{mM} \mathrm{NaCl})$, but were inhibited under severe salt stress [7]. The photosynthetic pigment results in this study were consistent with the results of ChlF. Siringam et al. [29] revealed that $\mathrm{Chl} a$ and total Chl were positively related to ChlF values.

There are many enzymes, such as APX, superoxide dismutase, glutathione peroxidase, and glutathione reductases involved in the enzymatic antioxidant pathway [5]. However, enzymes that require $\mathrm{K}^{+}$as a cofactor are more sensitive to high salinity [20]. APX participates in the ascorbate-glutathione pathway [49], and it has a $\mathrm{K}^{+}$binding site essential for APX activity [50]. $\mathrm{K}^{+}$ will be displaced by $\mathrm{Na}^{+}$at the essential binding site of APX, resulting in inhibited APX activity with increasing $\mathrm{Na}^{+}$concentrations when a plant is under $\mathrm{NaCl}$-induced stress. A recent study of Tahjib-UI-Arif [7] indicated that activities of APX, catalase, and peroxidase were significantly induced under salt salinity, but APX activity declined with increasing salinity level. A familiar result was 
also observed in this study (Figure 4). However, APX activity in seedlings with PEG treatments were inhibited more than from $\mathrm{NaCl}$ treatment at all iso-osmotic potential levels. This phenomenon indicated that ionic stress also served as environmental signal factor for induction of the mechanism against osmotic stress.

MDA, a product of lipid peroxidation, has been regarded as a good indicator of oxidative stress [51]. Many studies reported that salinity and drought significantly stimulated the accumulation of MDA coupled with an increase of proline in plant $[7,8,11]$. The results of the MDA determination in this study indicated that PEG treatments strongly induce lipid peroxidation and injure PEG-treated seedlings with higher PEG concentrations (Figure 5). However, stable MDA levels in NaCl-treated seedlings were observed among all osmotic potentials. The higher NPQ and Y(NPQ) values (Figure 3B,C) were correlated to the stable MDA levels in the NaCl-treated seedlings. These results suggest that wheat TCS2 seedlings needed the ionic stress as environmental signal to activate the mechanism to stabilize membrane system even under 250-300 $\mathrm{mM} \mathrm{NaCl}$.

Under osmotic stress, osmotic adjustment is accomplished by synthesizing osmolytes such as proline, glycine betaine, fructans, etc. [5,10]. Nxele et al. [8] observed a similar level of MDA in stressed plant under salinity and drought, but salinity stimulated more proline content. Recent study on wheat seedling also reported that $\mathrm{NaCl}$ stress stimulated proline accumulation dramatically, PEG induced accumulation of sugar metabolites (glucose, fructose) and glycine betaine, while polyamines' synthetic pathway was also altered by various osmolytes [26]. Furthermore, under salt stress, turgor would be maintained by transporters such as $\mathrm{Na}^{+} / \mathrm{H}^{+}$antiporter, $\mathrm{H}^{+}$-pyrophosphatase, high efficiency potassium transport [5], and aquaporin, which is specific transporter for water [6].

Shoot height in the PEG-treated seedlings was influenced more than in $\mathrm{NaCl}$-treated seedlings at all iso-osmotic levels, and root length in treated seedlings also showed a similar trend at osmotic level 1. Cell division and elongation are highly affected by water and/or osmotic stress, and are important for plant growth [52]. PEG treatments constrained the balance of turgor and resulted in poor shoot height performance. On the other hand, a higher shoot height in $\mathrm{NaCl}$-treated seedlings was observed because $\mathrm{NaCl}$ treatments provided $\mathrm{Na}^{+}$and $\mathrm{Cl}^{-}$as osmotics to reduce the osmotic stress in $\mathrm{NaCl}$-treated seedlings [12]. Root length is a vital trait reflecting the depth of the plant root in soil, and indicates how a plant functions under osmotic stress [53]. NaCl-treated seedlings performed better than PEG-treated seedlings at osmotic level 1, while there were no differences between treatments at osmotic level 2 and 3. This should be attributed to roots having a higher ability to adapt to osmotic stress [23]; therefore, root growth rate can be stably maintained under various levels of PEG-induced osmotic stress [54]. Moreover, recent study revealed that the biosynthetic pathway of polyamines, including spermine, spermidine and putrescine, which participate in cell division and differentiation [55], also mediated under osmotic stress, and PEG leaded to increase of spermine, spermidine and putrescine [26].

TCS2 grown under all PEG treatments had visual signs of wilting, indicating disabled water absorption. However, TSC2 remained vigorous under $\mathrm{NaCl}$ treatments, indicating it had the ability to cope with excess ion stress caused by $\mathrm{NaCl}$ application. This phenomenon was supported by the ChlF, photosynthetic pigments, APX activity, MDA concentration, and shoot lengths found in this study. Overall, NaCl-induced stress, as ionic signal, stimulated the wheat TCS2 seedlings to reduce lipid peroxidation for stabilization membrane system and photosynthetic functions, such as $\mathrm{F}_{\mathrm{v}} / \mathrm{F}_{\mathrm{m}}$ and photosynthetic pigments. These results help us to understand the mechanisms in salt-tolerant wheat cultivar TCS2 to adapt to osmotic stress and also revealed the physiological traits of TCS2 for further plant breeding.

\section{Conclusions}

The results of this study supported our hypothesis that TCS2 is more susceptible to osmotic stress than to ionic stress at three iso-osmotic levels of PEG and $\mathrm{NaCl}$ treatments. As a salt-tolerant wheat cultivar, the NaCl-treated TCS2 seedlings showed a higher ability to induce regulated non-photochemistry quenching in PSII (NPQ and Y(NPQ)) and APX activity to prevent lipid 
peroxidation and degradation of photosynthetic pigments. Therefore, these stabilized physiological functions leaded to the better performance of seedling growth.

Author Contributions: W.-D.H., C.-Y.L. and C.-C.C. conceived and designed the experiments. C.-Y.L. conducted the experiments, collected the data, and performed the analyses. W.-D.H., C.-L.C. and K.-H.L. provided the facilities and advised on the preparation of materials. C.-Y.L. and C.-C.C. edited the manuscript. All authors have read and agreed to the published version of the manuscript.

Funding: This research received no external funding.

Conflicts of Interest: The authors declare no competing financial interests.

\section{References}

1. Isayenkov, S. Physiological and molecular aspects of salt stress in plants. Cytol. Genet. 2012, 46, 302-318. [CrossRef]

2. Munns, R.; Sharp, R. Involvement of abscisic acid in controlling plant growth in soil of low water potential. Funct. Plant Biol. 1993, 20, 425-437. [CrossRef]

3. Filek, M.; Walas, S.; Mrowiec, H.; Rudolphy-Skórska, E.; Sieprawska, A.; Biesaga-Kościelniak, J. Membrane permeability and micro-and macroelement accumulation in spring wheat cultivars during the short-term effect of salinity-and PEG-induced water stress. Acta Physiol. Plant. 2012, 34, 985-995. [CrossRef]

4. Munns, R. Comparative physiology of salt and water stress. Plant Cell Environ. 2002, 25, 239-250. [CrossRef]

5. Agarwal, P.K.; Shukla, P.S.; Gupta, K.; Jha, B. Bioengineering for salinity tolerance in plants: State of the art. Mol. Biotechnol. 2013, 54, 102-123. [CrossRef]

6. Zhang, D.; Tong, J.; He, X.; Xu, Z.; Xu, L.; Wei, P.; Huang, Y.; Brestic, M.; Ma, H.; Shao, H. A novel soybean intrinsic protein gene, GmTIP2; 3, involved in responding to osmotic stress. Front. Plant Sci. 2016, 6, 1237. [CrossRef]

7. Tahjib-UI-Arif, M.; Sohag, A.A.M.; Afrin, S.; Bashar, K.K.; Afrin, T.; Mahamud, A.; Polash, M.A.S.; Hossain, M.; Sohel, M.; Taher, A. Differential response of sugar beet to long-term mild to severe salinity in a soil-pot culture. Agriculture 2019, 9, 223. [CrossRef]

8. Nxele, X.; Klein, A.; Ndimba, B. Drought and salinity stress alters ROS accumulation, water retention, and osmolyte content in sorghum plants. S. Afr. J. Bot. 2017, 108, 261-266. [CrossRef]

9. Almansouri, M.; Kinet, J.M.; Lutts, S. Effect of salt and osmotic stresses on germination in durum wheat (Triticum durum Desf.). Plant Soil 2001, 231, 243-254. [CrossRef]

10. Sayar, R.; Bchini, H.; Mosbahi, M.; Khemira, H. Response of durum wheat (Triticum durum Desf.) growth to salt and drought stresses. Czech J. Genet. Plant Breed. 2010, 46, 54-63. [CrossRef]

11. Marcińska, I.; Czyczyło-Mysza, I.; Skrzypek, E.; Filek, M.; Grzesiak, S.; Grzesiak, M.T.; Janowiak, F.; Hura, T.; Dziurka, M.; Dziurka, K. Impact of osmotic stress on physiological and biochemical characteristics in drought-susceptible and drought-resistant wheat genotypes. Acta Physiol. Plant. 2013, 35, 451-461. [CrossRef]

12. Huang, J.; Redmann, R. Salt tolerance of Hordeum and Brassica species during germination and early seedling growth. Can. J. Plant Sci. 1995, 75, 815-819. [CrossRef]

13. Rakhmankulova, Z.; Voronin, P.Y.; Shuyskaya, E.; Kuznetsova, N.; Zhukovskaya, N.; Toderich, K. Effect of $\mathrm{NaCl}$ and isoosmotic polyethylene glycol stress on gas exchange in shoots of the $\mathrm{C} 4$ xerohalophyte Haloxylon aphyllum (Chenopodiaceae). Photosynthetica 2014, 52, 437-443. [CrossRef]

14. Muranaka, S.; Shimizu, K.; Kato, M. Ionic and osmotic effects of salinity on single-leaf photosynthesis in two wheat cultivars with different drought tolerance. Photosynthetica 2002, 40, 201-207. [CrossRef]

15. Muranaka, S.; Shimizu, K.; Kato, M. A salt-tolerant cultivar of wheat maintains photosynthetic activity by suppressing sodium uptake. Photosynthetica 2002, 40, 505-515. [CrossRef]

16. Greenway, H.; Munns, R. Mechanisms of salt tolerance in nonhalophytes. Annu. Rev. Plant Physiol. 1980, 31, 149-190. [CrossRef]

17. Sharma, S.; Joshi, Y.; Bal, A. Osmotic and ionic effects in salt sensitive and resistant wheat varieties. Indian J. Plant Physiol. 1984, 27, 153-158.

18. Lutts, S.; Kinet, J.; Bouharmont, J. Changes in plant response to $\mathrm{NaCl}$ during development of rice (Oryza sativa L.) varieties differing in salinity resistance. J. Exp. Bot. 1995, 46, 1843-1852. [CrossRef] 
19. Borsani, O.; Valpuesta, V.; Botella, M.A. Evidence for a role of salicylic acid in the oxidative damage generated by $\mathrm{NaCl}$ and osmotic stress in Arabidopsis seedlings. Plant Physiol. 2001, 126, 1024-1030. [CrossRef]

20. Chaves, M.M.; Flexas, J.; Pinheiro, C. Photosynthesis under drought and salt stress: Regulation mechanisms from whole plant to cell. Ann. Bot. 2009, 103, 551-560. [CrossRef]

21. Munns, R. Genes and salt tolerance: Bringing them together. New Phytol. 2005, 167, 645-663. [CrossRef] [PubMed]

22. Yeo, A. Salinity resistance: Physiologies and prices. Physiol. Plant. 1983, 58, 214-222. [CrossRef]

23. Hsiao, T.C.; Acevedo, E.; Fereres, E.; Henderson, D. Water stress, growth and osmotic adjustment. Philos. Trans. R. Soc. Lond. B Biol. Sci. 1976, 273, 479-500.

24. Prat, D.; Fathi-Ettai, R.A. Variation in organic and mineral components in young Eucalyptus seedlings under saline stress. Physiol. Plant. 1990, 79, 479-486. [CrossRef]

25. Pérez-Alfocea, F.; Estan, M.; Caro, M.; Guerrier, G. Osmotic adjustment in Lycopersicon esculentum and L. Pennellii under $\mathrm{NaCl}$ and polyethylene glycol 6000 iso-osmotic stresses. Physiol. Plant. 1993, 87, $493-498$. [CrossRef]

26. Darko, E.; Végh, B.; Khalil, R.; Marček, T.; Szalai, G.; Pál, M.; Janda, T. Metabolic responses of wheat seedlings to osmotic stress induced by various osmolytes under iso-osmotic conditions. PLoS ONE 2019, 14, e0226151. [CrossRef]

27. Slama, I.; Ghnaya, T.; Savouré, A.; Abdelly, C. Combined effects of long-term salinity and soil drying on growth, water relations, nutrient status and proline accumulation of Sesuvium portulacastrum. C. R. Biol. 2008, 331, 442-451. [CrossRef]

28. Zörb, C.; Geilfus, C.M.; Dietz, K.J. Salinity and crop yield. Plant Biol. 2019, 21, 31-38. [CrossRef]

29. Siringam, K.; Juntawong, N.; Cha-um, S.; Kirdmanee, C. Relationships between sodium ion accumulation and physiological characteristics in rice (Oryza sativa L. spp. indica) seedlings grown under iso-osmotic salinity stress. Pak. J. Bot. 2009, 41, 1837-1850.

30. Sayar, R.; Khemira, H.; Kameli, A.; Mosbahi, M. Physiological tests as predictive appreciation for drought tolerance in durum wheat (Triticum durum Desf.). Agron. Res. 2008, 6, 79-90.

31. Dąbrowski, P.; Pawluśkiewicz, B.; Baczewska, A.H.; Oglecki, P.; Kalaji, H. Chlorophyll a fluorescence of perennial ryegrass (Lolium perenne L.) varieties under long term exposure to shade. Zemdirbyste 2015, 102. [CrossRef]

32. Dąbrowski, P.; Baczewska, A.; Pawluśkiewicz, B.; Paunov, M.; Alexantrov, V.; Goltsev, V.; Kalaji, M. Prompt chlorophyll a fluorescence as a rapid tool for diagnostic changes in PSII structure inhibited by salt stress in Perennial ryegrass. J. Photochem. Photobiol. B Biol. 2016, 157, 22-31. [CrossRef] [PubMed]

33. Kalaji, H.; Rastogi, A.; Živčák, M.; Brestic, M.; Daszkowska-Golec, A.; Sitko, K.; Alsharafa, K.; Lotfi, R.; Stypiński, P.; Samborska, I. Prompt chlorophyll fluorescence as a tool for crop phenotyping: An example of barley landraces exposed to various abiotic stress factors. Photosynthetica 2018, 56, 953-961. [CrossRef]

34. Faseela, P.; Sinisha, A.; Brestic, M.; Puthur, J. Special issue in honour of Prof. Reto J. Strasser-Chlorophyll a fluorescence parameters as indicators of a particular abiotic stress in rice. Photosynthetica 2019, 57, 108-115.

35. Dabrowski, P.; Kalaji, M.; Baczewska, A.; Pawluśkiewicz, B.; Mastalerczuk, G.; Borawska-Jarmułowicz, B.; Paunov, M.; Goltsev, V. Delayed chlorophyll a fluorescence, MR 820, and gas exchange changes in perennial ryegrass under salt stress. JLum 2017, 183, 322-333. [CrossRef]

36. Dąbrowski, P.; Baczewska-Dabrowska, A.H.; Kalaji, H.M.; Goltsev, V.; Paunov, M.; Rapacz, M.; Wójcik-Jagła, M.; Pawluśkiewicz, B.; Bąba, W.; Brestic, M. Exploration of chlorophyll a fluorescence and plant gas exchange parameters as indicators of drought tolerance in perennial ryegrass. Sensors 2019, 19, 2736. [CrossRef]

37. Kalaji, H.M.; Račková, L.; Paganová, V.; Swoczyna, T.; Rusinowski, S.; Sitko, K. Can chlorophyll-a fluorescence parameters be used as bio-indicators to distinguish between drought and salinity stress in Tilia cordata Mill? Environ. Exp. Bot. 2018, 152, 149-157. [CrossRef]

38. Lan, C.Y.; Lin, K.H.; Huang, W.D.; Chen, C.C. Protective effects of selenium on wheat seedlings under salt stress. Agronomy 2019, 9, 272. [CrossRef]

39. Zadoks, J.C.; Chang, T.T.; Konzak, C.F. A decimal code for the growth stages of cereals. Weed Res. 1974, 14, 415-421. [CrossRef]

40. Van Kooten, O.; Snel, J.F. The use of chlorophyll fluorescence nomenclature in plant stress physiology. Photosynth. Res. 1990, 25, 147-150. [CrossRef] 
41. Kramer, D.M.; Johnson, G.; Kiirats, O.; Edwards, G.E. New fluorescence parameters for the determination of QA redox state and excitation energy fluxes. Photosynth. Res. 2004, 79, 209. [CrossRef] [PubMed]

42. Nakano, Y.; Asada, K. Hydrogen peroxide is scavenged by ascorbate-specific peroxidase in spinach chloroplasts. Plant Cell Physiol. 1981, 22, 867-880.

43. Yang, C.M.; Chang, K.W.; Yin, M.H.; Huang, H.M. Methods for the determination of the chlorophylls and their derivatives. Taiwania 1998, 43, 116-122.

44. Heath, R.L.; Packer, L. Photoperoxidation in isolated chloroplasts: I. Kinetics and stoichiometry of fatty acid peroxidation. Arch. Biochem. Biophys. 1968, 125, 189-198. [CrossRef]

45. Sun, Y.; Xu, W.; Fan, A. Effects of salicylic acid on chlorophyll fluorescence and xanthophyll cycle in cucumber leaves under high temperature and strong light. J. Appl. Ecol. 2006, 17, 399-402.

46. Suriyan, C.U.; Chalermpol, K. Proline accumulation, photosynthetic abilities and growth characters of sugarcane (Saccharum officinarum L.) plantlets in response to iso-osmotic salt and water-deficit stress. Agric. Sci. China 2009, 8, 51-58. [CrossRef]

47. Flagella, Z.; Campanile, R.; Stoppelli, M.; De Caro, A.; Di Fonzo, N. Drought tolerance of photosynthetic electron transport under $\mathrm{CO}_{2}$-enriched and normal air in cereal species. Physiol. Plant. 1998, 104, 753-759. [CrossRef]

48. Siefermann-Harms, D. The light-harvesting and protective functions of carotenoids in photosynthetic membranes. Physiol. Plant. 1987, 69, 561-568. [CrossRef]

49. Wang, W.B.; Kim, Y.H.; Lee, H.S.; Kim, K.Y.; Deng, S.P.; Kwak, S.S. Analysis of antioxidant enzyme activity during germination of alfalfa under salt and drought stresses. Plant Physiol. Biochem. 2009, 47, 570-577. [CrossRef]

50. Pandey, S.; Fartyal, D.; Agarwal, A.; Shukla, T.; James, D.; Kaul, T.; Negi, Y.K.; Arora, S.; Reddy, M.K. Abiotic Stress tolerance in plants: Myriad roles of ascorbate peroxidase. Front. Plant Sci. 2017, 8, 581. [CrossRef]

51. Pinto, S.D.S.; Souza, A.E.D.; Oliva, M.A.; Pereira, E.G. Oxidative damage and photosynthetic impairment in tropical rice cultivars upon exposure to excess iron. Sci. Agric. 2016, 73, 217-226. [CrossRef]

52. Shao, H.B.; Chu, L.Y.; Jaleel, C.A.; Zhao, C.X. Water-deficit stress-induced anatomical changes in higher plants. C. R. Biol. 2008, 331, 215-225. [CrossRef] [PubMed]

53. Sayar, R.; Khemira, H.; Kharrat, M. Inheritance of deeper root length and grain yield in half-diallel durum wheat (Triticum durum) crosses. Ann. Appl. Biol. 2007, 151, 213-220. [CrossRef]

54. Greacen, E.; Oh, J. Physics of root growth. Nat. Cell Biol. 1972, 235, 24. [CrossRef] [PubMed]

55. Igarashi, K.; Kashiwagi, K. Polyamines: Mysterious Modulators of Cellular Functions. Biochem. Biophys. Res. Commun. 2000, 271, 559-564. [CrossRef] 